\title{
The influence of gamma rays and electric shock on seed germination and seedling growth in burdock plants
}

\author{
Mohammed Sabah Taher ${ }^{\star}$, Hussein Aneed Alamrani ${ }^{1}$, Issa Auuad Hassn², Israa Khalaf Aneed ${ }^{3}$, Batool Alaa Kadem \\ ${ }^{1}$ Unit of Medical and Aromatic Plants Research, College of Agriculture Engineering Sciences, University of Baghdad, Al-Jadiriya, Baghdad, Iraq. \\ ${ }^{2}$ Karbala Agriculture Directorate, Iraq. \\ ${ }^{3}$ Department of Medical Laboratory Techniques, Iraq \\ ${ }^{4}$ Department of Horticulture and Landscape Gardening. College of Agriculture Engineering Sciences, University of Baghdad, Al-Jadiriya, Baghdad, Iraq. \\ Corresponding author: mohammed.s@coagri.uobaghdad.edu.iq
} DOI. 10.21931/RB/2022.07.01.30

\begin{abstract}
Burdock plant is one of the important medicinal plants, the critical part of which is the roots used to clearance the body of toxins; the study aimed to stimulate burdock seed germination and seedling growth with low-cost treatments, represented by electric shock and irradiation with low doses of gamma rays on seeds. The experiment was implemented at the Medical and Aromatic Plants Research Unit, College of Agricultural Engineering Sciences, University of Baghdad, Iraq, in 2020. included 6 treatments: soaking the seeds with water for 12 hours only, an electric shock of the seeds ( 2 and 4 A) by soaking with water for 12 hours, irradiating the seeds (with 10, 20 or $30 \mathrm{~Gy}$ ) and soaking in the water for 12 hours. The experiment used the design of complete randomized (CRD) with three replicates. The results indicated that the highest germination percentage was recorded under the treatment of electric shock $(4 \mathrm{~A})$ and water soaking seeds only ( 91.0 and $85.7 \%$, respectively). On the other hand, the best germination speed was achieved when gamma rays were treated at (30 Gy) reached 5.93 days. The two treatments: seed irradiation (30 Gy) and water-soaked seeds, were distinguished in most of the seedlings' vegetative and root growth characteristics represented by the length of the seedlings, the number of leaves, and the soft, fresh and dry weight of the shoot and root systems. We conclude from the results that soaking the seeds with water before planting has a positive effect on increasing germination characteristics and seedlings, and the effect increases at treatment with gamma.
\end{abstract}

Key words: Burdock, electric shock, gamma rays, germination.

\section{Introduction}

Among the medicinal plants that have gained particular importance burdock plant (Arctium lappa L.) which belongs to the Asteraceae family. The critical part of the plant is the root, which contains many compounds such as Arctiin and Arctigenin, which have medical importance in the expulsion of toxic substances from the body and promoting blood circulation ${ }^{1}$ The presence of some phenolic compounds such as Chlorogenic acid and Caffeic acid increased the importance of the plant in scavenging free radicals ${ }^{2}$, which gives it importance in treating tumors resulting from inflammation. The plant extract (tea) is used to increase diuresis and reduce blood pressure and temperature, as well as the importance of the roots as antioxidants due to their content of derivatives of caffeoylquinic acid $^{3}$.

Because of the role of medicinal plants in supplying drug factories and the importance of this in preserving human life, the need arose to increase the qualitative and quantitative plant production starting from germination to yield by many agricultural processes, including some low-cost physical treatments such as the treatment of seeds by a stimulus by doses from gamma rays or electric shock ${ }^{4,5}$.

The effect of radiation on the plant is either stimulatory or inhibiting, or deadly. That effect depends on the radiation doses. Low doses stimulate plant growth, as exposing the seeds of some plants to low doses leads to an increase in the germi-

nation rate and the growth of the seedling. On the other hand, some studies indicate that radioactive activation has a temporary effect. It is believed that the difference in the results of radioactive activation is due to the influence of various factors such as the biological properties of the material exposed to radiation and its physiological condition, external factors such as humidity, temperature, lighting, and storage period before and after irradiation, irradiation dose rates, soil fertility, and genotype at the level of cultivars of the same species ${ }^{6}$.

Radiation with gamma rays affects the plant's phenotype and its anatomical, biochemical and physiological state depending on the irradiation dose. These effects include photosynthesis, cellular composition, metabolism, antioxidant system modeling and metabolism of phenolic compounds ${ }^{7-10}$. Induction begins by increasing the effectiveness of RNA synthesis or protein production that occurs during the early stages of seed germination and improvement in respiration and the auxin hormone metabolism in germinated seeds; this effect occurs in low doses of irradiation ${ }^{10}$.

In this path, many studies were applied; it was observed that there were differences in the effect of gamma rays according to the dose, plant type, and irradiation conditions. Nassar (2004) found that the treatment of seeds of (Chamomilla recutita L.) with gamma rays 0, 2, 4,6, 8 and $10 \mathrm{kr}$ (kilo rad $=1000$ rad) ) have improved the growth characteristics of plant height,

Citation: Sabah Taher M, Aneed Alamrani H, Auuad Hassn I, Khalaf Aneed I, Alaa Kadem B. The influence of gamma rays and electric shock on seed germination and seedling growth in burdock plants. Revis Bionatura 2022;7(1). 30. http://dx.doi.org/10.21931/RB/2022.07.01.30

Received: 17 July 2021 / Accepted: 7 November 2021 / Published: 15 February 2022

Publisher's Note: Bionatura stays neutral with regard to jurisdictional claims in published maps and institutional affiliations. 
the number of branches, dry weight and fresh weight of roots compared with plants produced from untreated seeds ${ }^{11}$. When exposing seeds of Foeniculum vulgare L. plant to different levels of gamma rays $0,20,40,60,80$, and 100 Gy $(\mathrm{Gy}=100$ rad ) Latif (2011) found an increase in weight of fresh and dry for vegetative growth were between the 60 and 80 Gy doses, while the 100 Gy dose inhibited growth ${ }^{12}$. On the other hand, a gradual decrease in the chlorophyll concentration was observed at the high dose of irradiation (200 Gy), which reached $14.2 \mathrm{mg} . \mathrm{Kg}^{-1}$ compared to $18.9 \mathrm{mg} . \mathrm{Kg}^{-1}$ at the dose of $100 \mathrm{~Gy}$ in the wheat plant ${ }^{13}$. Melki and Marouanig (2010) studied the effect of levels from gamma rays $(0,10,20,30 \mathrm{~Gy})$ on wheat germination and seedling growth in greenhouse conditions; they found a development in the number and length of roots by 18 and $32 \%$ respectively at dose $20 \mathrm{~Gy}^{14}$. Under laboratory conditions and field of experiment, were planted flax seeds irradiated with different doses by using ${ }^{60} \mathrm{Co}$ (cobalt element); it was noted that doses up to $8 \mathrm{Kr}$ were favorable in stimulating growth through the occurrence of significant differences in seed germination, branch length, the number of leaves and leaf area while the higher dose of $8 \mathrm{Kr}$ led to a negative effect on germination ${ }^{15}$.

About electric shock, Robert (2007) indicated that electro-shocked seeds had a high germination speed and an increased yield when using stable electricity, this reduced the chance of seeds dying, but the seeds must be moist because dried seeds may be damaged ${ }^{16}$. Sidaway (2009) exposed the seeds of Avena sativa plant to electricity and found high speed in the plant germination and increase in growth and dry weight $^{17}$. Al Taweel et al.(2018) showed that the best leaf area, chlorophyll content and dry weight of white and Egyptian henbane seedlings were at electric shock $2 \mathrm{~A}$ among three levels $(2,4,6 \mathrm{~A})^{18}$. Al-Mousawi (2017) showed that the electric shock treatment significantly affected vegetative and root growth indicators. The treatment of $4 \mathrm{~A}$ recorded the highest rates of vegetative growth indicators represented by plant height, the number of leaves, leaf area, fresh and dry weight of the Tannacetum parthenium L. plant ${ }^{5}$.

Based on the above, the study aimed to stimulate burdock seed germination and seedling growth with low-cost treatments, represented by electric shock and irradiation with low doses of gamma rays on seeds.

\section{Materials and methods}

The study was carried out to stimulate burdock seed germination and seedling growth by the effect of electric shock, gamma rays, and 12-hour soak in water. The seeds were obtained from the Medicinal and Aromatic Plants Research Unit, College of Agricultural Engineering Sciences, University of Baghdad. The seeds were divided into 18 groups according to the number of experimental units, and each group included 100 seeds. The experiment consisted of 6 treatments that included: soaking the seeds in water for 12 hours only, soaking in water for 12 hours, then shock electric of the seeds 2 and 4 $\mathrm{A}$ (Ampere), soaking in water for 12 hours then irradiating the seeds 10, 20 and 30 Gy (Gy=100 rad) with three replicate. The number of experimental units was 18 using the completely randomized design (CRD), and the characteristics were compared according to the LSD test at $5 \%{ }^{19}$.

Each group of seeds(100 seeds) was planted in plastic pots (15 D, $25 \mathrm{~L} \mathrm{~cm}$ ) in the plastic house on $25 / 11 / 2020$ using the peat moss substrate. The counting of the seeds was stopped when no new germination appeared for three days. Then, germination ratio (\%) and germination speed (day) were calculated. The seedlings were separated into plastic pots (8 D, $10 \mathrm{~L} \mathrm{~cm}$ ) for each plant in the pot (12 plants per treatment in the replicate) to make seedlings measurements. When the seedlings grew to about four true leaves, the parameters were measured: seedling length $(\mathrm{cm})$, root length $(\mathrm{cm})$, number of leaves, chlorophyll content (SPAD), fresh and dry weight of shoot(gm), fresh and dry root weight (gm).

Seeds were shocked in a glass container containing water (covering the seeds) with $(1 \% \mathrm{NaCl})$. Tow levels of shocking $(2$ and 4 amperes) were used for three minutes. Then the seeds were washed with water to remove the salt. As for irradiation treatments, the seeds were treated with gamma rays at the levels determined by using Cobalt 60 .

The germination percentage was daily calculated starting for the first germination until no seed was germinated for three days.

Germination percentage $=$ Number of germinated seeds / Total number of seeds $\times 100$

The speed of germination was calculated according to the following formula ${ }^{20}$.

$\mathrm{GS}=[(\mathrm{N} 1 \times \mathrm{D} 1)+(\mathrm{N} 2 \times \mathrm{D} 2)+\mathrm{Nn} \times \mathrm{Dn} \ldots . ..] / \mathrm{TG}$

GS: Germination speed.

$\mathrm{N}$ : Number of germinated seeds daily.

$D$ : Number of days from planting.

TG: Total number of germinated seeds

The seedling length was measured from the surface of the substrate to the top of the seedlings. Roots were separated from the shoot and washed with water to remove the remaining substrate. The roots were dried using a piece of cloth to remove the moisture. The fresh weight was measured using a sensitive balance. All shoots and roots were put in an oven at $\left(50^{\circ} \mathrm{C}\right)$ for drying. A sensitive balance measured the dry weight. (The average temperature inside the plastic house is about max. $21.5 \pm 1$ and $\min .11 .13 \pm 1$ )

\section{Results}

Figure (1.) shows a significant difference in the germination percentage due to the effect of the experimental factors. The highest germination percentage was achieved under the treatments of seeds shock ( $4 \mathrm{~A}$ ) and water-soaked seeds(91.0, $85.7 \%$, respectively). These were followed by the treatments gamma rays 20 and 30 Gy (76.0 and $75.7 \%$ respectively) compared to the lowest germination percentage under the treatment of gamma rays 10 Gy (72.0\%).

In the germination speed, figure (2.) noticed that the treatment of gamma rays 30 Gy achieved the highest germination speed (5.93 days) with a significant difference from the other treatments. This was followed by the treatments gamma rays 10 and 20 Gy (6.82 and 7.08 days respectively) compared with the lowest germination speed when seeds were soaked with water only(8.05 days).

\section{The treatments: 1 (soaking by water only) 2,3,4 (irradiation $10,20,30 \mathrm{~Gy}) 5,6$ (electric shock $2,4 \mathrm{~A}$ ) respectively.}

Although the highest level of chlorophyll was achieved at the treatments of shock the seeds $(4 \mathrm{~A})$ and gamma rays 20 Gy (49.13 and 45.8 SPAD respectively), they were not significantly different from the other treatments (Table 1).

In the number of leaves, it was noted from table 1 that the treatments of gamma-ray 30 Gy and electric shock (4 A) recorded the highest values (5.22 and 4.53 leaves. Seedlings ${ }^{-1}$ respectively), followed by the treatment of water-soaked 


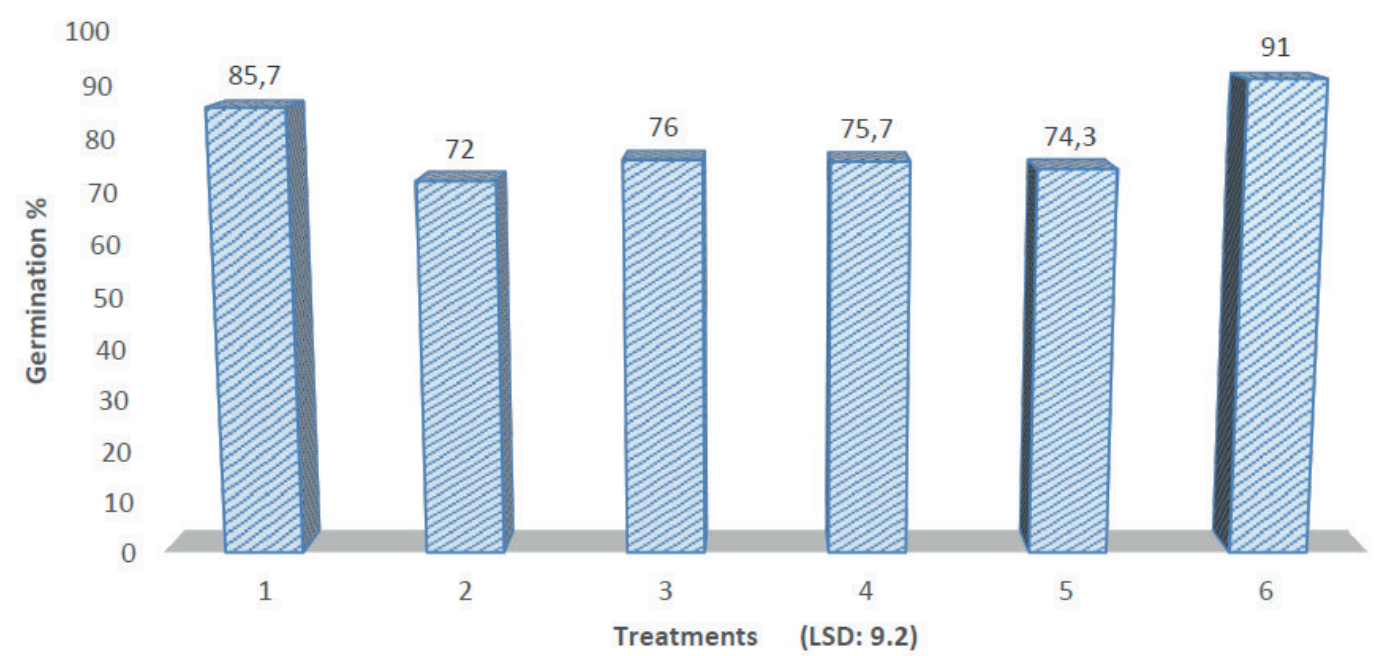

Figure 1. Effect of Gamma radiation and electric shock on germination \% (GP).

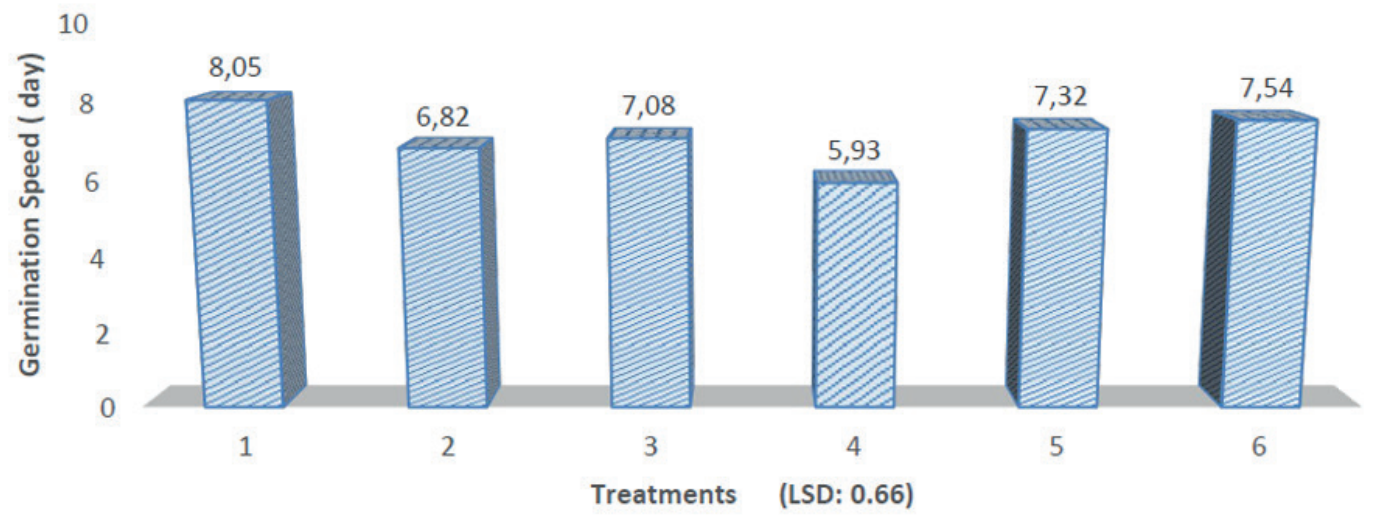

Figure 2. Effect of Gamma radiation and electric shock on germination speed (GS).

seeds (4.38 leaves. seedlings ${ }^{-1}$ ) compared with the lowest number of leaves when treated by gamma 20 Gy (3.61 leaves. seedlings ${ }^{-1}$ ).

From table 1 , the longest seedlings and the highest dry weight resulted from the treatment of water-soaked seeds (12.0 cm, $0.440 \mathrm{gm}$ respectively) and gamma rays $30 \mathrm{~Gy}$ ((11.16 cm, $0.415 \mathrm{gm}$ respectively), with a significant difference from other treatments. The shortest seedlings value was recorded under $4 \mathrm{~A}(6.00 \mathrm{~cm})$ treatment. However, the shocking seeds' lowest dry weight was recorded with 2A (0.150 $\mathrm{gm}$ ). The highest value of the fresh weight of seedling was 2.97 $\mathrm{gm}$ at the water-soaked treatment, followed by $2.64 \mathrm{gm}$ at the treatment of gamma rays $30 \mathrm{~Gy}$. Compared to the lowest value of the fresh weight, these were superior to $0.840 \mathrm{gm}$ at the treatment of shocking electric $4 \mathrm{~A}$.

Although the root length increased at the treatments ofgammarays30 Gy and electric shock 4A, it was not significantly different from the other treatments. The characteristics of the fresh and dry weight of roots recorded the highest values at the treatments of gamma rays 30 Gy $(3.43 \mathrm{gm}, 0.720$ gm respectively) and water-soaking (3.09 gm, 0.670 gm, respectively). These values were significantly different from the other treatments (Table 2).

\section{Discussion}

It is noted from the above that most of the characteristics of the study were improved by the effect of two treatments, water soaking and seed irradiating with 30 Gy. Soaking seeds by water before planting has a role in removing or reducing inhibitors concentration as well as softening the seed coat and increasing its permeability ${ }^{21}$. Therefore, it is easy to absorb water and oxygen to enter the seed embryos ${ }^{22}$, increasing the biological reactions leading to improved seedlings in the future. The characteristics' values were decreased under the rest of the treatments (10 Gy,20 Gy, 2 A, and 4 A). This decrease may be because these treatments are not suitable for stimulation, so the opposite ${ }^{6}$. As for the treatment of gamma rays, $30 \mathrm{~Gy}$, and water-soaking, the increase of germination speed and root characteristics may be due to the free radicals produced during the irradiation process, which may be necessary in stimulating metabolic processes it led to the germination process ${ }^{23}$. Also, the induction begins by increasing the effectiveness of RNA or protein synthesis that occurs during the early stages of seeds germination and improvement in respiration and auxin hormone metabolic in the germinated seed and reflection on the growth of roots and leaves. This effect occurs in low doses of irradiation ${ }^{10,24}$, as well as the improvement in the characteristics of vegetative growth (seedlings length, number of leaves, dry and soft weight of vegetative and root growth was reflected in the increase in the dry weight for root and vegetative characteristics.

\section{Conclusions}

The germination rate of seeds can be increased by some 


\begin{tabular}{|l|l|l|l|l|l}
\hline Treatment & $\begin{array}{l}\text { Height } \\
\text { (cm) }\end{array}$ & $\begin{array}{l}\text { Leaves No. } \\
\text { (leaf. } \\
\text { seedlings }\end{array}$ & $\begin{array}{l}\text { Chloroph } \\
\text { SPAD }\end{array}$ & $\begin{array}{l}\text { Fresh weig } \\
\text { (gm) }\end{array}$ & $\begin{array}{l}\text { Dry weigh } \\
\text { (gm) }\end{array}$ \\
\hline Soaking by water only & 12,0 & 4.38 & 42.27 & 2.97 & 0.440 \\
\hline Gamma ray 10 Gy & 6.62 & 3.94 & 43.33 & 0.880 & 0.160 \\
\hline Gamma ray 20 Gy & 7.12 & 3.61 & 45.80 & 0.845 & 0.175 \\
\hline Gamma ray 30 Gy & 11.16 & 5.22 & 44.0 & 2.64 & 0.415 \\
\hline Electric shock 2A & 6.75 & 3.94 & 43.23 & 0.845 & 0.150 \\
\hline Electric shock 4A & 6.00 & 4.53 & 49.13 & 0.840 & 0.175 \\
\hline L.S.D & $\mathbf{2 . 0 7}$ & $\mathbf{0 . 7 8}$ & $\mathbf{N . S}$ & $\mathbf{0 . 5 9 0}$ & $\mathbf{0 . 1 2 1}$ \\
\hline
\end{tabular}

Table 1. Effect of seed treatments on vegetative parameters of Arictum lapa seedlings.

\begin{tabular}{|l|l|l|l|}
\hline Treatment & Root length & $\begin{array}{l}\text { Root fresh } \\
\text { Weight }\end{array}$ & $\begin{array}{l}\text { Root Dry } \\
\text { Weight }\end{array}$ \\
\hline $\begin{array}{l}\text { soaking by water } \\
\text { only }\end{array}$ & 22.50 & 3.09 & $\mathbf{0 . 6 7 0}$ \\
\hline Gamma ray 10 Gy & 21.97 & 1.10 & $\mathbf{0 . 2 9 5}$ \\
\hline Gamma ray 20 Gy & 22.38 & 1.05 & $\mathbf{0 . 3 0 5}$ \\
\hline Gamma ray 30 Gy & 23.99 & 3.43 & $\mathbf{0 . 7 2 0}$ \\
\hline Electric shock 2A & 22.69 & 1.40 & $\mathbf{0 . 3 5 0}$ \\
\hline Electric shock 4A & 23.50 & 1.29 & $\mathbf{0 . 3 9 5}$ \\
\hline LSD & $\mathbf{N S}$ & $\mathbf{0 . 4 0}$ & $\mathbf{0 . 1 6 9}$ \\
\hline
\end{tabular}

Table 2. Effect of seeds treatments on root parameters of Arictum lapa seedlings.

simple treatments such as soaking with water before planting or treatment with some physical treatments (low cost) such as gamma rays and electric shock, but the appropriate dose must be determined because some doses lead to a negative effect. Our research has proven that the dose of 30 Gy was the best dose for germination and seedling characteristics of the burdock plant.

\section{Acknowledgments}

I hope thankful foe who support us to complete this research.

Funds

Self-funds.

\section{Conflict of interest}

Authors declare no conflicts of interest.

\section{Bibliographic references}

1. Chan Y S, Cheng L N, Wu J H, Chan E, Kwan Y W, Lee S Y, Leung G P, Yu P H, Chan S.W. A review of the pharmacological effects of Arctium lappa (burdock). Inflammopharmacology. 2010; 19(5): 245-54.

2. Anchena Fu, Bang An, Chau Wu, Chena Yang .The influence of different treatments on the free radical scavenging activity of burdock and variations of its active components. Food Chemistry. 2004; Volume 86, Issue 4 .Pages 479-484.

3. Predes F S, Ruiz A L, Carvalho J E, Foglio M A, Dolder H. Antioxidative and in vitro antiproliferative activity of Arctium lappa root extracts. BMC Complement Altern Med. 2011; 11: 25.

4. Al-Amrani H A H. The response of the Medicinal pumpkin to physical treatments and organic fertilizers, Ph.D. thesis, College of Agriculture, University of Baghdad. 2015; P 175.
5. Al-Mousawi Z J N. Influence of some physical and chemical factors on the production of the secondary metabolic compound from the Tanacetum parthenium L. planted field and laboratory. PhD thesis. college of Agriculture. Baghdad University. 2017; P 150.

6. Ibrahim A F, Al-Saadawi I S, Al-Janabi K K .. Applications of Nuclear Techniques in Plant Studies. Publications of the Iraqi Atomic Energy Organization. Babel Printing Press in Baghdad - AlSaadoun. 1990; p. 524

7. Kovács $E$, Keresztes A. Effect of gamma and UV- B/C radiation on plant cells. Micron, 2002; 33(2): 199-210.

8. Wi S G, Chung B Y, Kim J H, Baek M H, Yang D H, Lee J W, Kim J S. Ultrastructural changes of cell organelles in Arabidopsis stem after gamma irradiation. J. Plant Biol. 2005; 48(2):195-200.

9. Kim J H, Lee M H, Moon Y R, Kim J S, Wi S G, Kim TH, Chung B Y. Characterization of metabolic disturbances closely linked to the delayed senescence of Arabidopsis leaves after gamma-irradiation. Environ. Exp. Bot. 2009; 67(2): 363-371.

10. Jan S, Parween T, Siddiqi T O, Mahmooduzzafar. Effect of gamma radiation on morphological,biochemical, and physiological spects of plants and plant products .Environ. Rev. 2012; 20: 17-39.

11. Nassar H A, Hashim M F, Hassan N S, Ao-Zaid H. Effect of Gamma Irradiation and Phosphorus on Growth and Oil Production of Chamomile (Chamomilla recutita L. Rauschert). International.J of . Agr\&Biology. 2004; Vol. 6, No. 5.

12. Latif H H, Abdalla M A, Farag S A. Radio-stimulation of phytohormons and bioactive components of coriander seedlings Turkish Journal of Biochemistry-Turk. 2011; 36 (3) ; 230-236.

13. Borzouei A, Kafi M, Khazaei H, Naseriyan B, Majdabadi A. Effect gamma radiation on germination and physio- logical aspects of whweat (Triticum aestivum L.) seedlings . Pak. J. Bot. 2010; 42(4): 2281-2290.

14. Melki M, Marouani A. Effects of gamma rays irradiation on seed germination and growth of hard wheat. Environ Chem Lett. 2010; 8:307-310. 3. 
15. Ali H, Mumammad, Ullah R, Majeed A, Inayat N. Germination growth and yield performance flax (Linum usitatissimum L.) under gamma irradiation stress .2018;, No. 2 (174) /: 17-26.

16. Robert A N. Electro Culture (The Electical Tickle). USC. Section. 2007; 18(23):1-11.

17. Sidaway G H. Influence of Electrostatic Fields on seed Germination Department of Botony, University college. 2009; Cardiff DOI:10.1038/211303A0.

18. Al Taweel S K, Cheyed S H, Al Amrani H A. Effect of electric shock on germination and seedling growth in henbane species. Academia Journal of Medicinal Plants 2018; 6(5): 071-078.

19. Al-Rawi K M, Khalaf Allah A M. Design and analysis of agricultural experiments, second edition. Books and publishing house. University of Mosul - Iraq.p 2000; 488.

20.Czabator F J. Germination value: An index combining speed and completeness of pine seed germination. Forest Science. 1962; 8 : $386-395$.
21. Salman M A. Horticulture propagation. Ministry of Higher Education and Scientific Research. Baghdad University. the House of Books for Printing and Publishing. University of Al Mosul. 1988; P. 552.

22. Makhoul G, Ataff W. The effect of some physical and chemical treatments on the Guava seeds germination. Tishreen University Journal for Research and Scientific Studies - Biological Sciences Series Vol. 2016; (38) No. (1) .

23. Amjad. M , Anjum M A. Effect of gamma radiation on onion seed viability, germination potential, seedling and orfhology. l'ak J Agri S Vul. 2002; 39(3).

24. Minisi F A, El-mahrouk M E, El-Din M, Rida F, Nasr M N. Effects of Gamma Radiation on Germination, Growth Characteristics and Morphological Variations of Moluccella laevis L. American-Eurasian J. Agric. \& Environ. Sci. 2013; 13 (5): 696-704 . 